\title{
Cinsel İstismara Uğrayan İşitme Engelli Çocukların Adli Süreçte Yaşadığı Zorluklar: Bir Olgu Serisi
}

\author{
The Difficulties Sexually Abused Hearing Impaired Children in the Judicial Process: A Case \\ Series
}

\author{
Hatice Ünver ${ }^{1}$, Nesligül Nihal Olgun ${ }^{1}$, Şahika Gülen Şişmanlar ${ }^{1}$, Ayşen Coşkun ${ }^{1}$, Ümit Biçer ${ }^{2}$ \\ ${ }^{1}$ Kocaeli Üniversitesi Tip Fakültesi Çocuk Koruma Uygulama ve Araştırma Merkezi, Kocaeli \\ ${ }^{2}$ Kocaeli Üniversitesi Tip Fakültesi Adli Tip Anabilim Dalı, Kocaeli
}

\section{Özet}

Çocuğun cinsel istismarı, bir erişkinin cinsel gereksinim ve isteklerini karşılamak için çocukları ya da ergenleri araç olarak kullanmasıdır. Cinsel istismarın herhangi bir sosyodemografik grupla bağlantısı saptanmamış ve her sosyoekonomik düzeyde görülebileceği belirtilmiştir. Cinsel istismar tanısı genellikle çocuktan alınan öykü ile konulmaktadır. Cinsel istismarın tanısında ve değerlendirmesinde verbal iletişim çok önemli olduğundan, işitme engelli çocuklar diğer çocuklara göre daha fazla örselenmekte; kendilerini ifade edemedikleri için daha riskli duruma düşmektedirler.

$\mathrm{Bu}$ olgu serisinde cinsel istismara uğrayan işitme engelli üç çocuğun sosyodemografik özellikleriyle, tanı ve değerlendirme sürecinde yaşadıkları sıkıntılar ele alınarak; bu çocukların değerlendirmesinde dikkate alınacak yöntemler tartışılacaktır.

Çocuklarda cinsel istismar uzun dönem olumsuz sonuçlara yol açan önemli bir halk sağllğg sorunudur. Bu nedenle adli süreçte yer alan profesyonellerin eğitilmesi ve farkındalıklarının arttırılması çocukların sistem içerisinde daha rahat ve daha doğru değerlendirilmesine yardımcı olacaktır. ergen.

Anahtar kelimeler: Cinsel istismar, İşitme engeli, Çocuk ve

\section{Giriş}

Çocuğun cinsel istismarı, henüz cinsel gelişimini tamamlamamış çocuk ya da ergenin bir erişkin tarafından cinsel arzu ve gereksinimlerini karşılamak için güç kullanılarak, tehdit ya da kandırma yolu ile kullanılması olarak tanımlanmaktadır (1). Cinsel istismar sık rastlanan, genelde yıllarca süren bir durum olup sıklıkla gizli kalmaktadır. Olguların yalnızca \%15’inin bildirildiği düşünülmektedir (2). Kızlarda erkeklere oranla daha fazla görülmektedir. Pereda ve arkadaşları 2009 yılında cinsel istismar üzerine 21 ülkede yapılan 39 çalışmayı değerlendirmişlerdir. Bu değerlendirmede kızlarda cinsel istismar oranı \%10-20, erkeklerde ise \% 10 olarak saptanmıştır (3). Ülkemizde cinsel istismarın yaygın olduğu söylenmekle birlikte güvenilir veri

Sorumlu Yazar: Hatice Ünver

Kocaeli Üniversitesi Tip Fakültesi Çocuk Koruma Uygulama ve

Arasstırma Merkezi, Kocaeli

E-mail: drhaticeunver@gmail.com

Geliş: 21.11.2014

Düzeltme: 16.12.2014

\section{Abstract}

Sexual abuse means to meet sexual needs and desires of an adult with using children or adolescent. Sexual abuse was not detected in any sociodemographic groups and can be seen in every socioeconomic level. Diagnosis of sexual abuse is usually made with a history which taken from the child. Because of verbal communication is very important of evaluation in the diagnosis of sexual abuse; hearing impaired children are more abuse than other children and their inability to express themselves fell them in more risky situations.

In this case series; it is considering that sociodemographic characteristics and difficulties in the diagnosis and assessment process of 3 hearing impaired children who sexually abused and evaluation process will be discussed of these children.

Sexual abuse of children is an important public health problem that leads to long-term negative results. Therefore the training and raising awareness of professionals in the judicial process will help to evaluate more comfortable and accurate in the system of these children.

Keywords: Sexual abuse, Hearing impaired, Child and adolescent.

sayısı azdır. Çelik ve arkadaşlarının 2009 yılında yaptıkları çalışmada ülkemizdeki çocuk ve ergen psikiyatrisi kliniklerine yapılan adli başvuruların \% 81.3’ünün cinsel istismar olguları olduğu bildirilmiştir (4). Her yaştaki çocuğun cinsel istismara maruz kalabildiği, istismara maruz kalma yaşının ortalama 8-12 yaşlarında zirve yaptı̆̆ retardasyon, şizofreni, bipolar bozukluk, dikkat eksikliği hiperaktivite bozukluğu gibi ruhsal bozuklukların bulunması cinsel istismara uğrama riskini arttıran etmenlerdendir (6). Benzer şekilde işitme engelli çocukların fiziksel ve cinsel istismara iki kat daha fazla uğradığı bulunmuştur (7).

Konjenital işitme kaybı, konjenital anomaliler arasında en skk görülenlerden biridir. Yaklaşı her 1000 yenidoğandan 14'ünde görülmektedir. Bu oranın yenidoğan yoğun bakım ünitesinde tedavi gören bebeklerde daha yüksek olduğu bilinmektedir. Dil yeteneği ve becerilerinin kazanılabilmesi, çevreyle uyum, iletişim, zekâ, psikososyal gelişim açısından işitme duyusunun doğuştan itibaren normal sınırlarda olması 
gerekmektedir (8). İssitme duyusunun konjenital ya da edinsel kaybı çocuklarda zihinsel geriliğe neden olabilmektedir. Bu çocuklardaki kendini ifade etme güçlüğü her alanda zorluklar yaşamalarına; eğitimlerinin yarım kalmasına, tedavilerinin uygun şekilde yapılamamasına yol açabilmektedir.

$\mathrm{Bu}$ olgu serisinde Kocaeli Üniversitesi Çocuk Koruma Uygulama ve Araştırma Merkezi'ne başvuran cinsel istismar mağduru 3 işitme engelli çocuğun sosyodemografik özellikleri, yaşadıkları olayı algılama ve etkilenme düzeyleri ile adli değerlendirme sürecinde yaşadıkları zorluklar incelenmiştir.

\section{Olgu Sunumu \\ Olgu 1}

F. 16 yaşında, işitme engelli, erkek ergendi. Cinsel istismara uğradığı iddiasıyla ruhsal açıdan değerlendirilmek üzere Kocaeli Üniversitesi Çocuk Koruma Uygulama ve Araştırma Merkezi’ne yönlendirildi. Görüşmeye annesi, babası ve eğitim gördüğü özel eğitim ve rehabilitasyon merkezinde görevli, kendisinin tercümanlığını yapacak olan öğretmeni eşliğinde geldi. F. on aylıkken, ağır derecede işitme kaybı olduğu tespit edilmişti. Annesi ve babası F.'nin, altı yaşındayken işitme engeline yönelik bir özel eğitime başladığını, konuşmasının anlaşııı olmadığını, el işaretleri yardımıyla iletişim kurduklarını, ilköğretimi bitirdikten sonra çırak okuluna gitmeye başladığını ve berberde çalıştığını belirtiyordu. F. merkeze gelen ilk işitme engelli çocuktu. F.'nin başvuru yaptığ güne kadar engelli gruplara yönelik bir değerlendirme planı oluşturulmamıştı.

Annesi ve babası F.'nin, değerlendirmesinin yapıldığ 1 tarihten dört ay önce, daha önce tanıdığı on beş yaşındaki bir genç tarafından, tehdit edilerek, anal yoldan tecavüze uğradığını söylüyordu. F. ile tercüman eşliğinde yapılan görüssmede, kendisi de anne ve babasının anlattığı öykü ile uyumlu bir biçimde, el işaretleri ile yaşadığı olayı anlatıyor, bu gencin daha önce kendisine elle sataşmalarının - ensesini ve poposunu göstererek - olduğunu ifade etmeye çalışıyordu. Annesi, olay sonrasında F.'de sinirlilik, karşı gelme, kendine güvensizlik, karanlıktan ve yalnız kalmaktan korkma, huzursuzluk, yerinden sıçrama, olay yerinden geçerken tedirginlik, uyku düzensizliği ve belirgin iştah artışı gibi yakınmalarının başladığını, konuşamadığı için yaşadığı olayı el işaretleriyle tekrar tekrar anlatma ihtiyacı duyduğunu ifade ediyordu. F. ise ek olarak, yaşadığı olayın sık sık aklına geldiğini ve yoğun sıkıntı duyduğunu, olayla ilgili sürekli kabus gördüğünü, kendisini güçlendirme amacıyla barfiks çektiğini ve televizyonda dövüş programları izlediğini belirtiyordu. Görüşme boyunca hareketliydi. Oturduğu yerde sürekli kıpırdanıyor, görüşmeyi sık sık bölerek yaşadığ olayı defalarca anlatmaya çalışıyordu.
F.'nin hem kendi engel grubu içerisindeki gelişim özelliklerini öğrenmek hem de olay sonrası yaşadığı sorunlara ilişkin olarak daha ayrıntılı bilgi almak amacıyla tercümanı ile de görüş̧me yapıldı. Tercümanı, F.'nin diğer işitme engelli çocuklara göre akademik açıdan geri düzeyde kaldığııı, okuduğunu anlamakta zorlandığını ancak yazıları kopyalayabildiğini belirtiyordu. Yanısıra, işitme engelli çocuklarda iletişim kurarken her kelimenin eş değeri bir kelime kullanıldığını, F.'nin de bu kişiyi tanımlamak için penis işareti yaptığını, okula gelir gelmez sürekli olarak bu kişinin tutuklu olup olmamass ile ilgili defalarca soru sorduğunu, ders esnasında da dersi aniden yarım bırakarak yaşadığı olayı tekrar tekrar anlattığını, bu nedenle derse devam edemediklerini, dikkatinin çabuk dağıldığını, akademik olarak önceden yapabildiği ödevleri yapmakta zorlanmaya başladığını, arkadaşlarıyla birlikteyken eskisine göre daha hareketli olduğunu, zaman zaman kendisiyle göz göze geldiğini ve sürekli olarak iyi olduğunu belirtir tarzda el işareti yaptığını, böylece sıkıntısını belli etmemeye çalıştığını aktardı.

F., engeline eşlik eden zeka geriliği nedeniyle özbildirim ölçeklerini dolduramadı. "Good Enough İnsan Resmi Çiz Testi"nde çiziminin yaşına göre geri düzeyde olduğu gözlendi. İşitme engeli dolayısıyla öykü anlatması ile ilgili yönergelere uyum sağlayamadı. Yazısı da ilköğretim birinci sınıf düzeyindeydi. Zeka düzeyinin test sonucu ve klinik gözlemler doğrultusunda değerlendirildiğinde "orta düzeyde zeka geriliği" ile uyumlu olduğuna karar verildi. Yapılan ruhsal muayene ve psikolojik testler sonucunda F.'nin sergilediği belirtilere Travma Sonrası Stres Bozukluğu tanısı kondu.

\section{Olgu 2}

E. 9 yaşında, işitme engeli bulunan erkek çocuktu. Maruz kaldığ 1 iddia edilen cinsel istismarla ilgili olarak zeka testi ve psikiyatrik muayenesinin yapılması için merkezimize yönlendirildi. Görüşmeye annesi ile birlikte geldi. Kliniğe geldiği dönemde eğitimini sürdürdüğü özel eğitim ve rehabilitasyon merkezindeki işitme engelliler öğretmeninden alınan bilgiye göre, ileri derece işitme engeline - sol-107 dB; sağ-113 dB - sahipti. Kulaklık kullanıyordu ve konuşulan dili anlamakta belirgin güçlük yaşamıyordu. İşitme engeli nedeniyle okumayı tam olarak öğrenememişti. İkinci sınıftaydı ve okuma yazma çalışmalarına yeni başlamışlardı. Ancak görüşmede annesi aracilığılla işaretler, çlkarabildiği sesler ve kelimeler yardımıyla iletişim kuruldu. E. görüşmeler süresince iletişim kurmaya istekliydi. Resim ve oyun malzemelerine ilgi gösteriyor, görüşmecilerle oyun oynuyor ve daha çok günlük yaşamına dair konuları anlatmaya çalışıyordu.

Annesi E.'nin yıllardır komşuları olan bir ailenin on altı yaşındaki çocuğu tarafından, kendi evlerinde, anal yoldan 
cinsel istismara maruz kaldığını anlatıyordu. Olay sonrasında diğer çocuğa yönelik ailenin olumsuz tepkileri, konuşmalar, tutuklama gibi tüm yaşananlara E.'nin şahit olduğunu, bu nedenle kendisinin de tutuklanacağından korktuğunu belirtiyordu. Olay sonrasindaki ilk aylarda anneye korkulu gözlerle baktığ ${ }_{1}$, ebeveynlerin hafif kızgınlıklarında dahi "Dövme! Vurma!" diyerek kendini geri çektiği ve dayak yiyeceğini düşündüğü, sürekli korkar hale geldiği, geceleri inlediği, eski neşesinin azaldığı, okula tek gidememeye, yalnız kalmaktan korkmaya başladığı, artık annesinin kendisine

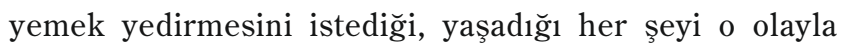
bağlantılandırdığı, o çocuk ve ailesiyle karşılaşmamaya çalıştığı ve karşılaşınca yüzlerine bakmadığı, bu nedenle evden çıkınca çok hızlı hareket etmeye çalıştı̆̆ı, sürekli iki polis ve bir insan resmi çizdiği, polis ve silahlara ilgisinin geliştiği, erkeklerden uzak durmaya çalıştı̆̆, olayla ilgili konuşulmasını istemediği ve hemen her gece altını ıslatmaya başladığı bilgisi alındı. Belirtilen yakınmaların zamanla azaldığı ancak olayla ilgili konuşmak istememe, olayı hatıllatan durumlar karşısında huzursuz olma, çocuk ve ailesiyle karşılaşmaktan çekinme, gece altını 1slatma, yalnız kalmaktan korkma gibi yakınmalarının sürdüğü ve okulda birkaç kez kızlar tuvaletine girdiği, kız arkadaşlarının poposuna dokunmaya çalışma şeklinde davranışlarının olduğu öğrenildi.

İșitme engelinin olması ve okuma yazma becerisinin henüz gelişmemesi nedeniyle özbildirim ölçeklerini dolduramadı. Zeka kapasitesinin değerlendirilmesi amacıyla uygulanan WISC-R performans alt testlerinin toplam puanı normal zeka düzeyine işaret etmekle birlikte işitme engeli nedeniyle uyumsal ve akademik alanlarda yaşıtlarının gerisinde performans sergilediği görüldü. Eğitim aldığı işaret dili ögretmeninin, E.'nin dil ve akademik gelişiminin yaşıtlarının gerisinde olduğunu belirtmesi değerlendirme sonucunu destekler nitelikteydi.

Ruhsal muayene ve psikometrik değerlendirmeler sonrasında E.'nin yaşadığı iddia edilen cinsel istismar sonrası sergilediği ruhsal belirtilere Travma Sonrası Stres Bozukluğu ve Sekonder Enürezis Nokturna tanıları konuldu ve belirlenen bu ruhsal bozuklukların tedavisine yönelik olarak "sağlık tedbiri”, ebeveynlerin olay sonrası çocuğa yaklaşımlarının düzenlenmesine katkı sağlamak amacıyla da "danışmanlık tedbiri” alınması uygun görüldü.

\section{Olgu 3}

M. 15 yaşında, işitme engelli kız ergendi. Babası tarafından cinsel istismara maruz kaldığ sağlığının değerlendirilmesi amacıyla merkezimize getirildi. M. ilkokulu ve ortaokulun son snıfını bir işitme engelliler okulunda okumuştu ve işaret dili biliyordu. İlk görüşmeye annesi eşliğinde geldi. Son birkaç aydır annesi ile birlikteydi. Altı yaşında annesi ve babası ayrıldıktan sonra babası ile yaşamaya başlamıştı. Annesi işaret dili bilmiyordu ancak aralarında bir iletişim yolu bulmuşlardı. M. ile zaman zaman annesinden yardım alarak zaman zaman da yazarak iletişime geçmeye çalışıldı. Ancak M. ile yaşanan iletişim güçlüğü, ergenin anlaşılması, karşılıklı bir güven ilişkisinin kurulması açısından engel teşkil ediyordu. M.'nin maruz kaldığı cinsel istismarın ayrıntılarına ilişkin daha güvenilir, sağlıklı bilgiler alınması ve M.'nin kendini daha rahat ifade edebilmesi amacıyla bir işaret dili tercümanının görüşmelere eşlik etmesi uygun görüldü ve ilgili mahkemeye bir tercümanın görevlendirilmesi için talepte bulunuldu. Bu talep üzerine mahkeme aracılığıyla görevlendirilen bir işaret dili tercümanı görüşmelere katıldı, M.'nin anlattıklarını tercüme etti. Mahkemenin görevlendirdiği tercüman M.'ye duruşmalarda da eşlik etmiş, ergenin güven duyduğu bir işaret dili tercümanıydı.

Alt1-yedi yaşlarından itibaren babasının cinsel istismarına maruz kaldığını belirtiyordu. Olaylara maruz kaldığı dönemde hep korktuğunu, kapısını kilitlediğini, babasının kendisine yaptıklarını rüyasında gördüğünü, onu gördüğünde çok rahatsız olduğunu, bayıldığını, annesinin yanında kalmaya başladığı andan itibaren daha rahat olduğunu ancak zaman zaman yaşadığı olayların aklına geldiğini, arada sırada olayları rüyasında gördüğünü, yemek yerken aklına geldiğini, çok sinirlendiğini, arkadaşlarına gitmek istemediğini, babasının yeniden gelmesinden endişelendiğini söyledi. Görüşme esnasında, yaşadığı olayı anlatırken heyecanlı, kaygılı ve öfkeli olduğu gözlendi. Annesi ile yapılan görüşmede, annesi M.'nin anlattığı bu şikayetlere ek olarak M.'nin en ufak şeye sinirlendiğini, tuvalette bile konuştuğunu, geceleri uyuyamadığ 1 nı, uykusunda sıçradığıını, yalnızken mastürbasyon yaptığını, yabancılardan çekindiğini ifade etti.

Uygulanan psikometrik testlerin sonucu zekası donuknormal zeka ile uyumluyken, klinik olarak kendi engel grubu içerisinde değerlendirildiğinde normal izlenimi veriyordu. İşaret dili tercümanının da yardımıyla öz bildirim ölçeklerinden “Cümle Tamamlama Testi”nin bazı maddelerini doldurmaya çalışt. Cümlelerinde özellikle babasına ilişkin ifadeler dikkat çekiyordu.

Ruhsal muayene ve psikometrik değerlendirmelerin sonucunda M.'ye Travma Sonrası Stres Bozukluğu ve Konversiyon Bozukluğu tanıları konulup, kendisine en yakın Çocuk Ruh Sağlığı kliniğinde tedavisinin başlatılması ve sürekliliğinin sağlanması için "sağlık tedbiri", annesinin M.'ye yönelik yaklaşımlarının düzenlenebilmesi için ise "danışmanlık tedbiri" alınması uygun görüldü. 


\section{Tartışma}

Çocukluk çă̆ı cinsel istismarı karmaşık nedenli, kısa ve uzun dönemde ruhsal yönden ağır olumsuz sonuçların yaşanmasına ve bireyin yaşam kalitesinin bozulmasına sebep olabilen ciddi bir psikososyal problemdir (9). Mental retardasyon, şizofreni, bipolar bozukluk, dikkat eksikliği hiperaktivite bozukluğu gibi ruhsal hastalıkları ya da engelliliği olan çocukların cinsel ya da fiziksel istismar mağduru olma riski diğer çocuklara göre artmıştır. Özellikle işitme engeli olan çocuklarda bu riski arttıran pek çok faktör bulunmaktadır. Öncelikle mağdurlar istismardan kaçamamakta ve istismara karşı korunmasız kalabilmektedirler. İletişim zorlukları istismarcıya karşı koymalarına ya da yardım istemek için bağırmalarına engel olabilmektedir. Hatta onlara ne olduğunu açıklamakta ciddi güçlük yaşamaktadırlar (10). Bu nedenle istismarın tanınması ve değerlendirilmesinde zorluklar ortaya çıkmaktadır.

Adli değerlendirmede bu çocukların özbildirim ölçeklerini yeterince dolduramadıkları, kendilerini daha iyi ifade etmelerine yardımcı olabilecek projektif testleri yapamadıkları ve zeka testini alamadıkları görülmektedir. Tercümanın ya da aile üyelerinden birinin üçüncü bir kişi olarak görüşmelere katılması görüşme kalitesinin bozulmasına, çocuğun kendini saklamasına, var olan belirtilerin atlanmasına ve terapötik ilişkinin yeterince kurulamamasına neden olmaktadır. Bu son derece sıkıntılı durum, klinik görüşmeleri sekteye uğratmakta, takip ve çocuğa destek aşamasını zorlaştırmaktadır. Benzer şekilde değerlendirme sürecinde alınan kararlar da etkilenmekte, çocuklar süreç içinde daha fazla örselenebilmektedir.

Kocaeli Üniversitesi Çocuk Koruma Uygulama ve Araştırma Merkezi'ne cinsel istismara uğrama nedeniyle gönderilen işitme engelli üç hastamızdan ikisiyle hem işitme engelli hem de dilsiz oldukları için mahkeme tarafından görevlendirilen işaret dili tercümanı ile görüşme yapılmış, birinin de görüşmesinde annesi bulunmuştur. Yaşadıkları olayları kötü olarak algıladıkları ancak ifade etmekte zorlandıkları, daha çok beden dilini kullandıkları gözlenmiştir. Üçüncü olgumuz M.'nin annesinin, M.'nin ifade etme güçlüğü nedeniyle yaşadıklarını uzun bir süre sonra öğrendiği gözlenmiştir. Olayların anlaşılması ve semptomların sorgulanmasında zorluklar yaşanmış, bu zorluklar adli raporda dile getirilmiştir. Mağdurlardan ikisi özbildirim ölçeklerini dolduramamış, birinin doldurabildiği cümle tamamlama testi de tercüman yardımıyla değerlendirilebilmiştir. İşaret dili tercümanından işitme engelli bireylerin kullandığ 1 işaret dili dilbilgisine dair alınan bilgiye göre, işaret dilinde cümleler devrik oluşturulmakta, kelimeler ek almamakta, konuşma dilinde kullanılan bazı ifadelerin de işaret dilinde karşılığı bulunmamaktaydı. Ülkemizde işitme engelli çocuk ve gençlerin zeka düzeylerinin değerlendirilmesi için bu engel grubuna özel geçerliliği ve güvenirliği yapılmış bir değerlendirme aracı bulunmadı̆̆ından, zeka kapasitesinin değerlendirilmesine yönelik olarak normal popülasyon için klinikte uygulanan WISC-R testi uygulandi. Ancak sözel alt testler işitme engeli nedeniyle standartlara uygun verilemeyeceği için yalnızca performans alt testleri uyguland. Her üç olguya travma sonrası stres bozukluğu tanısı konmuştur.

Adli değerlendirme sürecindeki polis, sosyal hizmet uzmanı, psikolog ve psikiyatrist gibi bu alanda çalışanların, çocukların ailelerinden alınan geri bildirimler üzerinden bilgi aktardıkları; işitme engelliliğine karşı sınırlı deneyimleri olduğu bilinmekte; bu nedenle çocukla iletişim kuracak işaret dili bilen uzmanlara olan ihtiyaç olduğu görülmektedir (11). İşaret dili bilen ya da dudak okuyabilen tercümanların az sayıda olması ve mahkemece görevlendirilmesinin beklenmesi süreci daha da zorlaştırmaktadır. Tercümanla yapılan görüşmelerde tercümandan alınan bilgiler değerlendirilmekte olup; bilgilerin çocuk tarafından sözel olarak aktarılamayışı merkezimizdeki psikoloğumuzun işaret dili kursuna başlaması gerekliliğini doğurmuştur.

Engelli çocuklarla yapılan görüşmelerde karşılaşılan zorluklar adli değerlendirmede raporlama, kayıt ve tedavi sürecini etkilemektedir. Özel durumdaki bu çocuklarla ilgili herhangi bir adli değerlendirme politikası ya da kılavuzun olmaması bu konuda çalışanları zor durumda bırakmaktadır. Mağdurların daha doğru ve daha iyi değerlendirilebilmesi için bu konuda çalışan profesyonellerin eğitilmesi ve farkındalıklarının arttırılması gerekmekte; işaret dili eğitimi almaları gibi önlemlerin alınması, tanı koymaya ve tedaviye yardımcı ölçeklerin ve zeka testlerinin geliştirilmesi, görsel ve anatomik materyallerin bulundurulması gerekmektedir.

\section{Kaynaklar}

1. İşeri E. Cinsel İstismar. Çetin FÇ, Pehlivantürk $\mathrm{B}$, Ünal $\mathrm{F}$ ve ark. (ed). Çocuk ve Ergen Psikiyatrisi Temel Kitabı içinde. 1. Baskı, Ankara, Hekimler Yayın Birliği 2008; 470-477.

2. Taner Y, Bahar G. Çocuk istismarı ve ihmali: psikiyatrik yönleri. Hacettepe Tip Dergisi 2004; 35: 82-86.

3. Pereda N, Guilera G, Forms M, Gomez- Benito J. The international epidemiology of child sexual abuse: a continuation of Finkelhor. Child Abuse Negl 2009; 33:331-342.

4. Çelik G, Tahiroğlu A, Avcı A, Seydaoğlu G. Çocuk ve ergen ruh sağlığ ${ }_{1}$ kliniğine başvuran ergen hastaların özellikleri. Yeni Symposium 2009; vol 47; no:3.

5. Özen NE, Şener Ş. Cocuk ve ergende cinsel istismar. Ege Psikiyatri Sürekli Yayınları 1997; 2: 473-491.

6. Bahar G, Savaş A, Bahar A. Çocuk istismarı ve ihmali: Bir gözden geçirme. Furat Sağlık Hizmetleri Dergisi 2009; 4(12):51-65.

7. Schwenke T. Childhood Trauma: Considering diagnostic and culturally sensitive treatment approaches for deaf clients. JADARA 2011; vol 45: 158-169. 
8. Yazgan H, Keleş E, Gebeşçi A. Yenidoğan işitme taramasında dört yıllık sonuçlarımız. Van Tıp Dergisi 2012; 19(3):112-115.

9. Davis KM, Gidyez CA. Child sexual abuse prevention programmes: A metaanalysis. Journal of Clinical Child Psychiology 2000; 29: 257265.
10. Temkin J. Disability, child abuse and criminal justice. The Modern Law Review 1994; 402-418.

11. Chacko MR, Buttler JT, Kirkland RT. Communication and special health care needs of a profoundly hearing impaired adolescent. Clinical Pediatrics 1987; vol26(8):395-397. 